\title{
Correction to: Guideline for the diagnosis of drug hypersensitivity reactions
}

\author{
Knut Brockow · Bernhard Przybilla - Werner Aberer · Andreas J. Bircher · Randolf Brehler · Heinrich Dickel · \\ Thomas Fuchs · Thilo Jakob · Lars Lange · Wolfgang Pfützner · Maja Mockenhaupt · Hagen Ott • Oliver Pfaar · \\ Johannes Ring · Bernhardt Sachs · Helmut Sitter · Axel Trautmann · Regina Treudler - Bettina Wedi · \\ Margitta Worm - Gerda Wurpts · Torsten Zuberbier · Hans F. Merk
}

Published online: 6 December 2017

(C) Springer Medizin Verlag GmbH 2017

The online version of the original article can be found under https://doi.org/10.1007/s40629-015-0052-6.

\section{Prof. Dr. K. Brockow $(\bowtie) \cdot J$. Ring}

Department of Dermatology and Allergology am

Biederstein, Technische Universität München, Biedersteiner Straße 29, 80802 Munich, Germany

knut.brockow@tum.de

\section{B. Przybilla}

Department of Dermatology and Allergology, Allergy Center, Ludwig Maximilian University of Munich, Munich, Germany

\section{W. Aberer}

Department of Dermatology, Medical University of Graz, Graz, Austria

\section{A. J. Bircher}

Department of Allergology, University Hospital Basle, Basel, Switzerland

\section{R. Brehler}

Department of Dermatology, Münster University Hospital, Münster, Germany

\section{H. Dickel}

Department of Dermatology, Venereology and Allergology, St. Josef Hospital, Ruhr University Bochum, Bochum, Germany

\section{T. Fuchs}

Department of Dermatology, Venereology and Allergology, Göttingen University Hospital, Göttingen, Germany

T. Jakob

Department of Dermatology and Venereology, Freiburg University Hospital, Freiburg, Germany

\section{Lange}

Department of Pediatrics, Marien Hospital, Bonn, Germany

\section{W. Pfützner}

Department of Dermatology and Allergology, Gießen and Marburg University Hospital, Marburg, Germany

\author{
M. Mockenhaupt \\ German Center for the Documentation of Severe Skin \\ Reactions, Department of Dermatology and Venereology, \\ Freiburg University Hospital, Freiburg, Germany \\ H. Ott \\ Children's and Adolescents' Hospital "Auf der Bult", \\ Hannover, Germany

\section{O. Pfaar} \\ Center for Rhinology and Allergology, ENT at Mannheim \\ University Hospital, Wiesbaden, Germany \\ B. Sachs \\ Federal Institute for Drugs and Medicinal Products, Bonn, \\ Germany
}

\section{H. Sitter}

Institute of Theoretical Surgery, Philipps University, Marburg, Germany

A. Trautmann

Department of Dermatology and Allergology, Mainfranken Allergy, Würzburg University Hospital, Würzburg, Germany

R. Treudler

Department of Dermatology, Venereology and Allergology, Leipzig University, Leipzig, Germany

B. Wedi

Department of Dermatology, Venereology and Allergology, Hannover Medical University, Hannover, Germany

M. Worm · T. Zuberbier

Department of Dermatology, Venereology and Allergology,

Charité University Hospital, Berlin, Germany

G. Wurpts · H. F. Merk

Department of Dermatology and Allergology, RTWH

Aachen, Aachen, Germany 
Correction to:

\section{Allergo J Int 2015}

DOI https://doi.org/10.1007/s40629-015-0052-6

In the original published version, Tab. 4, first two lines, the names of the in Europe currently comercially available $B$-Lactam antibiotics were not given correctly. Furthermore, the corresponding values of the prick test and intradermal test concentrations were published wrongly. The correct table is given here.
Suspected drug hypersensitivity reactions require allergological investigation in order, firstly, to prevent severe reactions upon renewed exposure or, secondly, to avoid unnecessary drug restrictions. Skin tests are important to detect sensitization to drugs. The methods described by the European Network on Drug Allergy (ENDA) in several guidelines and position papers are currently recommended. In 2003, an error concerning testing for beta-lactam allergy found its way into these recommendations stating incorrect test concentrations for the two commercial penicillin test

Table 4 Non-irritant skin test concentrations of frequently tested drugs [4]

\begin{tabular}{|c|c|c|c|}
\hline Drug or drug class & Prick test & Intradermal test $^{\mathrm{h}}$ & Patch test \\
\hline \multicolumn{4}{|l|}{ B-Lactam antibiotics } \\
\hline Benzylpenicilloyl-octa-L-lysine & $8.6 \times 10^{-5} \mathrm{~mol} / \mathrm{L}$ & $8.6 \times 10^{-5} \mathrm{~mol} / \mathrm{L}$ & NA \\
\hline Sodium benzylpenilloate & $1.5 \times 10^{-3} \mathrm{~mol} / \mathrm{L}$ & $1.5 \times 10^{-3} \mathrm{~mol} / \mathrm{L}$ & NA \\
\hline Benzylpenicillin & $10,000 \mathrm{IU} / \mathrm{ml}$ & $10,000 \mathrm{IU} / \mathrm{ml}$ & $5 \%$ \\
\hline Amoxicillin & $20 \mathrm{mg} / \mathrm{ml}$ & $20 \mathrm{mg} / \mathrm{ml}$ & $5 \%$ \\
\hline Ampicillin & $20 \mathrm{mg} / \mathrm{ml}$ & $20 \mathrm{mg} / \mathrm{ml}$ & $5 \%$ \\
\hline Cephalosporins & $2 \mathrm{mg} / \mathrm{ml}$ & $2 \mathrm{mg} / \mathrm{ml}$ & $5 \%$ \\
\hline \multicolumn{4}{|l|}{ Anticoagulants } \\
\hline Heparins $^{\mathrm{a}}$ & Undiluted $^{\mathrm{h}}$ & $1 / 10$ diluted & Undiluted $^{\text {h }}$ \\
\hline Heparinoids ${ }^{b}$ & Undiluted $^{\mathrm{h}}$ & $1 / 10$ diluted & Undiluted $^{\mathrm{h}}$ \\
\hline \multicolumn{4}{|l|}{ Platinum salts } \\
\hline Carboplatin & $10 \mathrm{mg} / \mathrm{ml}$ & $1 \mathrm{mg} / \mathrm{ml}$ & NA \\
\hline Oxaliplatin & $1 \mathrm{mg} / \mathrm{ml}$ & $0.1 \mathrm{mg} / \mathrm{ml}$ & NA \\
\hline Cisplatin & $1 \mathrm{mg} / \mathrm{ml}$ & $0.1 \mathrm{mg} / \mathrm{ml}$ & NA \\
\hline \multicolumn{4}{|l|}{ NSAIDs } \\
\hline Pyrazolones ${ }^{c}$ & Suspension ${ }^{\mathrm{i}}$ & $0.1-1 \mathrm{mg} / \mathrm{ml}$ & $10 \%$ \\
\hline Coxibs $^{d}$ & Suspension ${ }^{i}$ & NA & $10 \%$ \\
\hline Other NSAID & Suspension ${ }^{\mathrm{i}}$ & $0.1-1 \mathrm{mg} / \mathrm{ml}$ & $10 \%$ \\
\hline \multicolumn{4}{|l|}{ Biologicals } \\
\hline Adalimumab & $50 \mathrm{mg} / \mathrm{ml}$ & $50 \mathrm{mg} / \mathrm{ml}$ & Undiluted $^{\text {h }}$ \\
\hline Etanercept & $25 \mathrm{mg} / \mathrm{ml}$ & $5 \mathrm{mg} / \mathrm{ml}$ & NA \\
\hline Infliximab & $10 \mathrm{mg} / \mathrm{ml}$ & $10 \mathrm{mg} / \mathrm{ml}$ & NA \\
\hline Omalizumab & $1.25 \mu \mathrm{g} / \mathrm{ml}$ & $1.25 \mu \mathrm{g} / \mathrm{ml}$ & NA \\
\hline \multicolumn{4}{|l|}{ Others } \\
\hline Local anesthetics & Undiluted $^{\mathrm{h}}$ & $1 / 10$ diluted & Undiluted $^{\mathrm{h}}$ \\
\hline lodinated contrast media & Undiluted $^{\mathrm{h}}$ & $1 / 10$ diluted & Undiluted $^{\mathrm{h}}$ \\
\hline Gadolinium chelates & Undiluted $^{\text {h }}$ & $1 / 10$ diluted & NA \\
\hline Patent blue & Undiluted & 1/10 diluted & NA \\
\hline Methylene blue & Undiluted & $1 / 100$ diluted & NA \\
\hline Fluorescein & Undiluted $^{\mathrm{h}}$ & $1 / 10$ diluted & Undiluted $^{\mathrm{h}}$ \\
\hline Proton pump inhibitors ${ }^{f}$ & Undiluted $^{\mathrm{h}}$ & $40 \mathrm{mg} / \mathrm{ml}$ & $10 \%$ \\
\hline Anticonvulsants ${ }^{g}$ & $N A$ & NA & $10 \%$ \\
\hline Chlorhexidine digluconate & $5 \mathrm{mg} / \mathrm{ml}$ & $0.002 \mathrm{mg} / \mathrm{ml}$ & $1 \%$ \\
\hline $\begin{array}{l}\text { NA not applicable or no recomm } \\
{ }^{\text {a}} \text { Heparins: unfractionated hepari } \\
\text { bHeparinoids: danaparoid, fonda } \\
{ }^{\mathrm{c}} \text { Pyrazolones: metamizole, propy } \\
{ }^{\mathrm{d}} \text { Coxibs: celecoxib, etoricoxib, va } \\
{ }^{\mathrm{e}} \text { Other NSAIDs: e. g., aspirin, ibu } \\
{ }^{\mathrm{f}} \text { No intravenous solution availabl } \\
{ }^{9} \text { Test initially with } 1 \% \text { in the cas } \\
{ }^{\mathrm{h}} \text { Use of the commercially availab } \\
\text { 'Tablet is ground to a powder an }\end{array}$ & $\begin{array}{l}\text { ration, NSAID non-s } \\
\text { dalteparin, enoxapa } \\
\text { inopyrine, phenazc } \\
\text { en, indomethacin, c } \\
\text { al testing with lans } \\
\text { ctions } \\
\text { intravenous infusior }\end{array}$ & $\begin{array}{l}\text { meloxicam, mefen } \\
\text { ole, only for prick t } \\
\text { ection }\end{array}$ & enia \\
\hline
\end{tabular}


kits available in Europe at that time [1]; this error was then copied in several position papers [2-4], as well as in the "Guideline for the diagnosis of drug hypersensitivity reactions" [5]. In these documents, reagent concentrations were incorrectly expressed in $\mathrm{mmol} / \mathrm{L}$, instead of $\mathrm{mol} / \mathrm{L}$. Regarding the available commercial test kits, one producer has discontinued the production of their kits (Alleropen, Allergopharma, Germany). The other test kit was modified in 2012 and is available since then with a higher purified formulation of the major determinant benzylpenilloyl-octaL-lysine instead of benzylpenilloyl-poly-L-lysine and improved stability using sodium benzylpenicilloate as the single minor determinant instead of a minor determinant mixture (DAP ${ }^{\circledR}$ Kit, Diater, Madrid, Spain). It is currently the only commercially available test kit in Europe.

The correction relates to the major determinant (benzylpenicilloyl octa-L-lysine) and the minor determinant (sodium benzylpenilloate). They are present following reconstruction in $1 \mathrm{ml}$ solvent at concentrations of $8.6 \times 10^{-5} \mathrm{~mol} / \mathrm{L}$ (related to eight benzylpenicilloyl moieties) and $1.5 \times 10^{-3} \mathrm{~mol} / \mathrm{L}$ (for sodium benzylpenilloate) and not, as given in the relevant overview articles, $5 \times 10^{-5} \mathrm{mM}$ penicilloyl poly-L-lysine and $2 \times 10^{-2} \mathrm{mM}$ for the minor determinant mixture. Thus, the data in Table 4 need to be corrected accordingly. Compliance with the written instructions enclosed with the DAP ${ }^{\circledR}$ Penicillin Test Kit automatically yields the correct test concentrations. The corrected version of Table 4 can be found above.

\section{References}

1. Torres MJ, Blanca M, FernandezJ, RomanoA, WeckA, Aberer $\mathrm{W}$, et al. Diagnosis of immediate allergic reactions to betalactam antibiotics. Allergy. 2003;58:961-72.

2. Romano A, Blanca M, Torres MJ, Bircher A, Aberer W, Brockow K, et al. Diagnosis of nonimmediate reactions to beta-lactam antibiotics. Allergy. 2004;59:1153-60.

3. Blanca M, Romano A, Torres MJ, Fernandez J, Mayorga C, Rodriguez J, et al. Update on the evaluation of hypersensitivity reactions to betalactams. Allergy. 2009;64:183-93.

4. Brockow K, Garvey LH, Aberer W, Atanaskovic-Markovic M, Barbaud A, Bilo MB, et al. Skin test concentrations for systemically administered drugs-an ENDA/EAACI Drug Allergy Interest Group position paper. Allergy. 2013;68:702-12.

5. Brockow K, Przybilla B, Aberer W, Bircher AJ, Brehler R, Dickel H, et al. Guideline for the diagnosis of drug hypersensitivity reactions: S2K-Guideline of the German Society for Allergology and Clinical Immunology (DGAKI) and the German Dermatological Society (DDG) in collaboration with the Association of German Allergologists (AeDA), the German Society for Pediatric Allergology and Environmental Medicine (GPA), the German Contact Dermatitis Research Group (DKG), the Swiss Society for Allergy and Immunology (SGAI), the Austrian Society for Allergology and Immunology (ÖGAI), the German Academy of Allergology and Environmental Medicine (DAAU), the German Center for Documentation of Severe Skin Reactions and the German Federal Institute for Drugs and Medical Products (BfArM). Allergo J Int. 2015;24:94-105. 